\title{
SELF-ATTENTION IN PREGNANCY FOR WOMEN LIVING IN RURAL AREA: A ETHNOGRAPHIC STUDY ${ }^{1}$
}

\author{
Isabel Cristina Pacheco Van der Sand², Lúcia Beatriz Ressel ${ }^{3}$, Marisa Monticellit $^{4}$ Janine Schirmer ${ }^{5}$
}

\begin{abstract}
${ }^{1}$ Text extracted from dissertation - Significados culturais do processo do nascimento para mulheres do campo, presented to the Programa de Pós-Graduação em Enfermagem, Doutorado Interinstitucional/(Dinter) Novas Fronteiras, Universidade Federal de São Paulo, Universidade Federal do Rio de Janeiro, Universidade Federal de Santa Maria, in 2014.

2 Ph.D. in Sciences. Professor, Universidade Federal de Santa Maria (UFSM), Campus de Palmeira das Missões. Palmeira das Missões, Rio Grande do Sul, Brazil. E-mail: isabelvan@gmail.com

${ }^{3}$ Ph.D. in Nursing. Professor in UFSM. Santa Maria, Rio Grande do Sul, Brazil. E-mail: lbressel208@yahoo.com.br

${ }^{4}$ Ph.D. in Nursing. Retired professor,Programa de Pós-Graduação em Enfermagem, Universidade Federal de Santa Catarina. Florianópolis, Santa Catarina, Brazil. E-mail: marisamonticelli123@gmail.com

${ }^{5}$ Ph.D. in Nursing. Professor, Escola Paulista de Enfermagem, Universidade Federal de São Paulo. São Paulo, São Paulo, Brazil. E-mail: schirmer.janine@unifesp.br
\end{abstract}

\begin{abstract}
: the study aims to recognizing self-attention practices related to pregnancy by women from rural area, as well as identifying these practices according to the different models of attention to health/birth. We carried out ethnography in three rural communities in a small city in the North Region of Rio Grande do Sul State. Seventeen informants participated in the study. Data were collected by the Observation-Participation-Reflection model and ethnographic interviews. For the analysis, the model chosen was Madeleine Leninger's. Results show that, for these women, being pregnant means a question of health; however, they develop practices of self-care that are created in the tension between popular knowledge and Biomedicine recommendations for health promotion. Thus, pregnant women avoid carrying weight, reduce physical activities and change some eating habits. At the same time, they have prenatal care, highlighting the importance of technological apparatus and the status of the authoritative knowledge of Biomedicine.
\end{abstract}

DESCRIPTORS: Pregnancy. Nursing. Cultural anthropology. Rural population

\section{AUTOATENÇÃO NA GRAVIDEZ PARA MULHERES RESIDENTES NO CAMPO: UM ESTUDO ETNOGRÁFICO}

\begin{abstract}
RESUMO: estudo com o objetivo de conhecer as práticas de autoatenção relativas à gestação produzidas por mulheres do campo, bem como a identificação dessas práticas com os diferentes modelos de atenção à saúde/nascimento. Trata-se de uma etnografia realizada em três comunidades rurais de pequeno município do Norte do Rio Grande do Sul. Participaram 17 informantes. Nacoleta de dados, utilizaram-se técnicas de Observação-Participação-Reflexão e entrevistas etnográficas. No processo analítico, utilizou-se a análise temática de Leininger. Os resultados mostraram que, para essas mulheres, estar grávida significa vivenciar saúde; no entanto, as gestantes desenvolvem práticas de autoatenção que são articuladas na tensão entre os conhecimentos familiares/populares e os da biomedicina. Desta forma, evitam carregar peso, diminuem esforços físicos e mudam alguns hábitos alimentares. Ao mesmo tempo, realizam acompanhamento pré-natal, valorizando sobremaneira o aparato tecnológico e o status autoritativo da biomedicina.
\end{abstract}

DESCRITORES: Gravidez. Enfermagem. Antropologia cultural. População rural.

\section{AUTOATENCIÓN EN EL EMBARAZO DE MUJERES RURALES: UN ESTUDIO ETNOGRÁFICO}

RESUMEN: Estudio que objetivó conocer las prácticas de auto-atención relativas al embarazo de mujeres campesinas, así como la identificación de esas prácticas con los distintos modelos de atención a la salud/nacimiento. Se trata de una etnografía realizada en tres comunidades rurales de un pequeño municipio del Norte del Estado del Rio Grande do Sul. Participaron 17 informantes. En la recolección de los datos se utilizaron técnicas de Observación-Participación-Reflexión y encuestas etnográficas. En el proceso analítico, se utilizó el análisis temático de Leininger. Los resultados muestran que, para esas mujeres, estar embarazada significa estar saludable, sin embargo, las mujeres embarazadas desarrollan prácticas de autoatención que son articuladas en los conocimientos familiares/populares y los de la biomedicina. Así, evitan cargar peso, disminuyen esfuerzos físicos y cambian algunos hábitos alimentarios. Al mismo tiempo, realizan acompañamiento prenatal, valorizando de sobremanera el aparato tecnológico y el status autoritativo de la biomedicina.

DESCRIPTORES: Embarazo. Enfermería. Antropología cultural. Población rural. 


\section{INTRODUCTION}

The interest in the subject of this study - selfattention practices related to pregnancy, conducted by rural women - is justified due to the prenatal care to the population residing in rural areas, when compared to women in the urban context, despite an increase in the number of consultations between 2000 and 2005, compared with the first five years of the previous decade ${ }^{2}$ still has deficit results. ${ }^{1}$ It is noticed that the experience of pregnancy, understood as an event that integrates the process of birth is influenced by, in addition to individual, social and historical reasons, by the symbolic universe of interactions held by women, including different models of health care.

Despite these changes, and the existence of classical and/or international studies on reproductive health, from a cultural perspective, ${ }^{3-4}$ there are few investigations involving Brazilian women living in the countryside that address this theme and with this approach. Accordingly, in a reflective analysis publication, ${ }^{5}$ it mentions that in the catalogs of theses and dissertations of The Nursing Study and Research Center, available online between 2008 and 2012 (excluding the 2011 catalog, which is not available), there are four studies relating to pregnancy issues related to culture. Of this group, three of them are published in the form of paper, and one refers to "the knowledge and care practices that permeate the pregnancies of women attending Basic Health Units, another refers to a review of the cultural influences in the eating habits of pregnant teenagers and the last is about the body and the physiological processes during pregnancy and its repercussions on sexuality". 5:2897 None of these productions include women living in the countryside.

It is noteworthy that one of the authors of this study exercises their professional activities in the Rio Grande do Sul region (RS) with strong rural characteristics, which justifies the relevance of the investigations aimed at the rural population. So for these reasons, and sustained by the realization that specific cultural knowledge can inform strategies for improving the health of populations, in which pregnant rural women are included, this study's guiding question is: how do the practices of self-attention, relating to pregnancy, conducted by rural women, identify with the health care models? The objective of this study is to understand the self-attention practices related to pregnancy performed by rural women, as well as the identification of these practices with the different models of health care/birth

\section{THEORETICAL REFERENCE}

To meet this goal, a theoretical matrix of health anthropology contributions was used,in particular the critical aspect of Eduardo Menéndez Spina. ${ }^{6-7}$ The choice of this reference was anchored, among other reasons, because the experience of pregnancy is multidimensional discussing issues relating to culture which in this study, refers to a network of meanings contained in symbolic systems and established socially, in terms of what people act and interact. ${ }^{8}$ This experience has peculiar characteristics in different communities and in the same community, because of numerous components, among which are those relating to health and their different models of care.

Menendez defends the existence of a plurality of health care models, which are permeable to each other and are used by the population simultaneously or sequentially over time, articulated by self--attention. ${ }^{6-7}$ The understanding of the healthdisease-attention process should be based on the dialectic subject-structure and the hegemony-subordinate relationship between the models of care, particularly the hegemonic medical model, which is anchored in the biomedical paradigm and model of self-attention. ${ }^{6}$ Self-Attention refers to meanings and practices used in the subject's level and the social group to face the processes that affect their health in real or imaginary terms, without the intervention of specialists, even when they are recommended for this activity. ${ }^{7}$ It can be given in a broad and narrow sense. Primarily, self-attention refers to meanings and practices for ensuring the bio-social reproduction at the level of micro-groups, especially domestic, operated from the objectives and standards established in the culture. In an order restricted specifically aimed at coping with ailments. ${ }^{7}$

\section{METHOD}

An ethnographic study developed between August 2012 and January 2014, the general locality was a northern municipality of the RS, which has 4,098 inhabitants, of which $63.7 \%$ lived in the countryside. Of these residents in the country, 1,248 were women, and 1,179 were between ten to 70 years of age or more. ${ }^{9}$ The focused scenario of the study consisted of sites which operated practices of selfattention at birth, ie three communities where the key informants of the study lived, and other health care environments, particularly pre-natal care.

The city has two teams belonging to the Family Health Strategy (ESF) which give 100\% coverage of 
the population and are allocated to the same physical and urban area. Prenatal care for non-risk pregnancies in the Family Health Strategy (ESF) teams, is preformed through medical consultations and pregnant women groups (one each semester), which are coordinated by a nurse and with the participation of different health professionals, which in one of each eight meetings, discusses topics related to pregnancy and childbirth relating to their specialty. The dynamics of the meetings varies from lectures to strategies considered more interactive and dialogical. High-risk pregnancies are referred to more complex services located in other municipalities, but maintain ties with the Family Health Strategy (ESF), through groups of pregnant women (if the clinical condition allows), home visits and access to the Family Health Strategy (ESF) if necessary. Due to the municipality not providing delivery care at the local hospital, the non-risk pregnancies are referred to a municipality starting from 6 months gestation, both with which the Municipal Health Department has an agreement via the Intermunicipal Consortium of Health, in order that the patient is accompanied by the professional obstetrician who will assist in the labour. This monitoring takes place in the private practice of this doctor. The average distance between the overall locality and these services is 31 kilometers. The referenced pregnant woman continues to be accompanied in the Family Health Strategy ESF which is obligatory.

The definition of key informants (women who wanted to participate and dominated the theme) ${ }^{10}$ occurred in the ethnographic process, not a priori. Thus, some informants, through exposure of their ideas and practices have been building a dialogical relationship with the researcher which contributed to qualifying their listening and ensuring a "real" interaction, ${ }^{11}$ which showed that they mastered the subject and could be the key informants. The selection of these women was guided also by the following criteria: 1) are experiencing the process of birth (pregnancy or the postpartum period) or are significant people for these women (like a sister, for example, even if she had not had children), or even , are women who had already experienced the PN at some earlier point in life. 2) reside in one of three rural locations listed for the study, to be born there or have established ties, regardless of union with someone else from the location.

The decision for women experiencing PN, and not only those who had already experienced, was guided in particular by the importance of the inclusion of social practices in the ethnography production, since without them the researcher was likely to be based on what informants said they did and not on what they really did. ${ }^{6}$ Self-attention practices, being relational, ${ }^{6-7}$ reinforced the need to observe them, which would only occur if some key informants were experiencing PN. Through the perspectives and different uses of the significant actors, it was possible to detect the range of connections made between the different forms of attention to face the health problems. ${ }^{7}$ This was the reason for the inclusion of significant persons of the pregnant and postpartum women.

As for general informants (those with general ideas on the subject) ${ }^{10}$ professionals in prenatal care, relatives and neighbors of the key informants were included, since they were willing to contribute to the investigation. ${ }^{10}$

Thus, the study counts, 17 informants in total: ten key informants and seven general informants. Of the key informants, two were pregnant, two in the postpartum period, three were significant people and three were women who had already experienced the PN (mother, grandmother and greatgrandmother). The average age of these women was 43.6 years (minimum of 22 and maximum of 75 years). One of them was a widow and the others were married.

We opted for the Observation-Participation -Reflection model (OPR) as the main technique of data collection. ${ }^{10,12}$ In the first two phases of the OPR model, the researcher did not stay in the field continuously, but in order to operationalize the 3rd and 4th stages the researcher alternated the days remaining in the scenario (two to three days per week, including weekends), spent the night in the shelter of the home of one of the key informants, an invitation, which took place during the nine months. This informant, after the researcher explored the study design in the meeting, was the first to accept the invitation to participate. At first, she was counted on as a general informant, followed by guidelines for ethnographic studies, ${ }^{11}$ however, after a few meetings, when she showed to be a "true conversationalist," 10 and to have profound knowledge of the subject matter, she was included as a key informant, due to welcoming and accepting the researcher whenever she went to the countryside, in a close acquaintance with the three communities.

From there, the researcher coexisted with other key informants, participating in activities in the domestic scene (chimarrão rounds, prayers, teas, helping in house activities, shopping in the supermarket, birthdays) and the collective scene (political 
meetings, activities of health and education promotion, religious events). The key informants were followed in prenatal consultations and groups of pregnant women in childbirth care and when they returned home after delivery.

The OPR was supplemented by ethnographic interviews. For those who were shaping up as key informants made at least three interviews. At first they were asked to tell a little of themselves in an attempt to adjust to the audio interview being recorded. The second was guided by the following challenge: "Tell me about your experience of pregnancy, since you started thinking about becoming pregnant or suspected you were pregnant, until today." The third was an opportunity for the resumption and deepening of issues that have arisen in the OPR process, specific questions like: "Last week, I realized that you asked for help to bring the milk pails into the house. Was this due to something in particular?" Some general informants (relatives and / or neighbors) were interviewed to deepen emerging themes of the OPR and/or interviews with key informants. There was use of field diary.

In the analytical process we chose the thematic analysis ${ }^{10.12-13}$, composed of 1) collection and description of the raw data in the information obtained by data collection techniques which were recorded, searching in a preliminary way to identify, starting from the focus $\mathrm{emic}^{10}$ (point of view of the informants, i.e. internal constructs of the group culture), and the etic size ${ }^{10}$ (using the lenses of the theoretical framework adopted), the symbols and contextual meanings related to phenomena; 2) identification and characterization of components and descriptors when emic and etic descriptors were sought from similarities and differences between the information obtained and their meanings; 3) contextual analysis and recurring patterns when they examined data in the search for saturated ideas and recurring meanings , similar or different, focusing on expressions, structural forms or explanations related to the field of research, validating the results with the informants; and 4) identification of relevant themes and theoretical formulations, corresponding to the highest stage of the analysis.

It is noteworthy that among the rigorous criteria adopted in this study, as recommended for ethno nursing ${ }^{10}$ validation was performed through the confirmability when the researcher is repeatedly with informants in order to reaffirm what he heard, saw or experienced in relation to the phenomena under study. Thus, during the data collection process, checking the interpretations that were being operated in the interim, in a kind of "microvalidation" manner was performed. At one point, the research report with partial results was brought to each key informant in order to confirm the recurring patterns and possible themes. The final report was read by three key informants, seeking confirmability of the findings.

The research project was approved by the Ethical Research Committee of the Universidade Federal de São Paulo, under required protocol 81600. Fulfilling the ethical principles of Resolution. 196/96.14 in force at the time of data collection, the key informants signed an Informed Consent Form. The general informants, who only observed gave verbal permission to do so, and those who were interviewed, were also asked to sign the consent form.

\section{RESULTS AND DISCUSSION}

Starting with the cultural patterns "Pregnancy is health, not a disease," "Pregnancy is health, but must take care not to endanger the baby and the pregnant woman" and "To care for the pregnancy it is necessary to have an ultrasound," the theme of this article emerged topic: "Pregnancy is health, but there has to be family care and care of the doctor."

When referring to pregnancy, the key informants refer to those daily chores, stating that they hardly took care in relation to their pregnancy because they worked during that period. Being able to work and doing it without rest in pregnancy is associated with being healthy: I dug, planted using the machine, washed clothes. I never had any threat of losing of my seven children. I never saw a doctor during pregnancy (Key Informant, 75); if I stand still, then I get sick. I always worked, because I'm pregnant, I'm not sick (Key Informant. 34).

Work is a social value that is part of the ethos of the group studied, i.e., what unites them, beyond the moral and aesthetic aspects of a given culture, identifying values. ${ }^{8}$ Exaltation of this value seems to represent cultural heritage of the occupation times of the municipality, which included the participation of older women in the scene, which helped parents in the conquest of the place of residence and for farming work. This participation appears partly linked to certain conditions related to the difficulties in a time of poverty. The testimony of one of the key informants, referring to the family of origin, gives clues to this inference. Her narrative begins with matters relating to work and then is associated with pregnancy, which, reaffirming a cultural standard, does not connote disease and, in her particular case, did not require care. 
We have always had poor means, we worked with our parents in the fields, from the age of eight. The boys were small and the father took the daughters to work in the fields. [...] Pregnant women were always working. With the plow cable, the hoe, breaking corn, carts ... and then unloading. I cut down bushes, cut firewood. The precautions of today didn't exist then. Many feel that pregnancy is a disease, but I do not. I've always had healthy pregnancies, I never went the doctor, not for anything, I never had anything (Key Informant, 63).

The tacit association "work-health-pregnancy," related, among others, to the social, economic and occupational of the group study, constitutes element that, in some way, define what they mean by a sick or healthy person and consequently mediates the actions and interventions that consider appropriate to the health/birth and decisions by certain models of atention. ${ }^{7}$ This association is part of the social and symbolic realities that interfere in some way, in the intentional nature of the practices that the group of informants operate in relation to pregnancy, i.e. in self-attention practices whose recognition and understanding by experts of the health sector, which includes nurses, is of importance for the realization of culturally congruent and competent care practices.

In addition to the significances regarding the work, which are explored in the rural women's experience, who routinely, face the triple work load which is heavy and demands physical effort, the meanings connected to pregnancy, maternity and child, who are shared by the social group of informants, also strengthen and mediate self-attention practices related to pregnancy. These meanings report that, although pregnancy symbolizes a condition of being healthy some practices aimed at maintaining and/or promotion of this "state" are required, so that "being pregnant" minimally affects the normal course of life, also ensuring the health of the fetus.

Thus, almost all women in the study avoid physical exertion, heavy lifting and change some eating habits during pregnancy: still working there with the aunt, but now I began to care for myself, I don't lift things a lot, I go slower. I help with the milk, but I don't carry the pails, I do not want to lose the baby (Key Informant, 24 years).

Additionally, young women attending antenatal services, which care practices are anchored primarily in the medical hegemonic model. For this, they have the support and monitoring of older women in the group, despite these ladies, while referring to their own pregnancies, mentioned that little care would be needed in that period. This care, revealing a practice of self-attention seems to indicate a recognition by the older women of the group, that biomedicine resources are, at present, a citizenship right that should be taken advantage of during pregnancy: my mother said that pregnant women shouldn't bend down much until they are four months pregnant. They taught us how to pick up weight, and if we were to take something that was high up, she said not to force our arms. At that time there were a lot of babies being lost, due to lack of treatment due to lack of experience, then we had to find a way to take care of ourselves. Nowadays there are resources. Women have to do prenatal care, take care of themselves (Key Informant, 61).

It also contributes to the formation of this cultural pattern, which states that women need to take some care to promote and maintain healthy pregnancy, the fact that the creation of new families is a social value of the group and, in this context, women have the central role with a view to ensuring that value, which is associated to including the identity and the female role within the group. In this logic, interaction with family and friends and interpretation of events happening with their body, pregnant women formulated indicative explanatory models which could represent certain behaviors which may pose a risk to the baby and therefore modulates self- attention practices with preventive purpose.

I went by bike to work up to five months pregnant, but I was afraid of bumps. They said I could lose the baby. I started to drive because my belly was already heavy, the bike bumps hurt me (Key Informant, 27); I walked with malaise, swollen. It wasn't a pain in the belly, they weren't contractions. I had gas, because of the soda. So I avoid soda, coffee, matte tea. I feel like she shakes when I take these things, she moves a lot. I realized and I started to look after myself (Key Informant, 34).

In addition to the formulation of explanatory models and self-attention practices, women seek to validate them, which what mainly happens is the exchange of knowledge with people from their family group, friends, other pregnant women and also the search for guidance from the SS experts: They [the mothers and mothers-in-law] always say something like not to lift much weight. They say that lifting too much weight, makes the umbilical cord become thick and it takes a long time for it to fall. My mother says it and I hear it. [...] Why do you want to insist? This here [Referring to the current pregnancy] is already different because the doctor also says, 'do not lift too much weight. 'I feel that when I lift weight, the baby stirs a lot (Informant key, 34); in the prenatal consultation in the 
Family Health Strategy, listening to medical advice that we should lead a normal life, one informant said that her family doesn't let her ride a motorcycle anymore, the doctor stresses that this is a relevant concern to the family because the roads are in poor condition, it is not even advisable that a pregnant woman rides a motorcycle, the pregnant woman nods, seeming to be convinced.(Field diary. Key Informant, 24 years).

At a meeting of the pregnant women group, sponsored by Family Health Strategy ESF, participants complained about the older women of the family who tried to prevent them from leading a normal life, one of the key informants said: I can't not do anything, I will slow down, but I'm not sick, I keep doing my activities (Field Journal, Key Informant, 34). Faced with confrontations that circulated in the group, the professional who coordinated the meeting, referred to the doctor in authority several times to define what can and what cannot be done during pregnancy: Life continues as normal throughout pregnancy, unless your doctor tells you otherwise. The doctor will know what you can or cannot do (Field Journal, General Informant).

The data allow us to interpret what the rural women connect the family/popular knowledge with the biomedical model, which aims to incorporate legitimized practices in the social environment of operation, and which protects the health of the child, ensuring the fulfillment of its social role and preserves the normality of life.

The explanatory models that justify self-attention practices operated by the key informants may differ from those produced within the health sector; however, its formulation is not distanced from the interactions held by individuals and their social groups with experts in this sector. The set of informants operates, cultural knowledge from different sectors of health care / birth in its own way, not considered antagonistic. ${ }^{7}$ In fact, this knowledge is reinterpreted and transformed into self-attention practices to meet the needs and demands of pregnancy.

It is noted that the elaborations of the key informants were produced in a distinct way than what was operated at the meeting of the Family Health Strategy group of pregnant women, in which, despite all the coordination effort so that the meeting was conducted from experiences the participants with an appreciation of their experiences, there was a hierarchy of knowledge. This ranking seems to be a product and reflection of the relations produced in the health sector. In this perspective, the PN is medicalized, so that the women's right to make decisions and have autonomy in relation to their health and their life, is reduced. Their knowledge is placed in a subordinate position, holding the relationship of dominance/subordination of the biomedical model on other forms of non-medical care, reducing the possibilities of using not identify with this practice model. ${ }^{7}$

Despite this trend, the connections made by the key informants in this study in relation to care during pregnancy, result in forms of self-attention in clear transactional dynamics, which occurs to the extent that they and their social groups live in one space, and another for health care for births (health sector/family sector) ${ }^{6-7}$ In this movement, every environment of care presents itself as a "model" of knowledge ${ }^{8}$ which, after suffering a subjective and symbolic filtering of the subject and their social groups, are possibly incorporated in a resignified way, and they constitute "models of " care $^{8}$ in pregnancy. Through this process, this "new" knowledge will inform the self-attention practices concerning pregnancy, largely modeled in a lato sense and not strict, until the dynamics of relationships and life itself, were to produce other knowledge that, with the previous knowledge or substituting it, which will also constitute in "models" and "models of" the culture of care and attention to pregnancy. The first I had no follow-up, I didn't find it necessary. But having follow up care in pregnancies in the past, it helped me a lot, I took a test which showed anemia. So they told me to eat differently they gave me vitamins, iron, to strengthen me. The children were born stronger. The previous babies looked healthy, but they were weak. The doctor directed us to take all the medication and we took it (Key Informant, 61); The mother and the doctor say it's not good... So now, I try not to lift too much weight, not to make much effort. To twist a cloth or bend over, I do it in a special way. But I help in my way. I work with the cows, it is a good walk and it does me good.. I help get milk, but I don't carry the pails. Pregnancy does not prevent anything, it is not a disease (Key Informant, 34).

It is noteworthy that in some interactions that occurred in the research stage, the informants were suspicious of the knowledge from another sector that was not the SS. One of the key informants, living with children who dominated the knowledge of classical science, referring to the teachings of her mother puts into question all of this knowledge, when she expressed herself as follows: she said it was better not to force in pregnancy because it forces the body. I do not know if it was true! (Key Informant, 61).

It emphasizes the possible effect of the presence of the researcher on the informants in a qualitative research approach, which can expect the approval of the first and their opinions and behaviors 
expressed in the interaction research. Thus, if the expression of the informant had that sense and meaning, it does not cease to declare the hierarchical position between these two knowledges, stated through the narrative.

In the study of the scene, some tension was perceived between the different knowledge which circulated, since in the plurality of self-attention practices operated by rural women ,sometimes health sector knowledge surpasses themselves about the others, it is the family/ popular knowledge which guides decisions regarding pregnancy.

The understanding of the biomedical knowledge circulating in the scenario under consideration, especially during pregnancy, often as hegemonic knowledge, which uses a hierarchical status, reasserts itself when the repertoire of almost all informants, emerges the expression " ultrasound". Ultrasonography (USG) is a symbol of biomedicine which gives it the "power" to give "certainty", freeing the social subjects of anguish of "the unknown" or "the unexpected" and therefore an important device in the production of meanings and self-care practices related to pregnancy: I had an ultrasound once per month. At the end, I had one more than once per month. The morphological one, I did that, to see the neck and to see about Down syndrome and the little heart also (Key Informant, 32).

In a pre-natal consultations observed in the general scenario of the referenced study, instead of a traditional obstetrical physical examination, the pregnant woman, after being weighed, steps up on the examination table and without the doctor's request raises the bottom of the shirt, leaving the abdomen on display for ultrasound examination: the doctor says, 'it is already in the birth position with the head down'. The informant says, 'then she turned around because she was sitting.' The doctor replies: 'Yes, the head is here. Look, opening the little mouth. The back is on the left. Here are the ribs, the heart. Here see the labia majora. It's approximately 2,500 grams, it will reach about three kilos and 100 grams. In two weeks it will no longer be premature '(Field diary. Key Informant, 34).

Rural women, similar to most women of her time, assume, unconsciously, that they need machine assistance to "work well" and bring healthy children into the world. Thus, placed in a position of double dependence of this fact, because, in addition to the machine, the physician is required to interpret the exam results. ${ }^{15-16}$ And in the middle of this complex network, within it, a 'need' for monitoring and surveillance of the health of women and children is produced, the $\mathrm{PN},{ }^{15-16}$ and her pregnancy, an experience of transformation, therefore, carries uncertainties, and is considered a medical event, controlled and free of tensions.

In this approach, the health care practice, commonly, stay away from pregnant women, as a woman and other persons with whom it maintains bonds of affection and with whom pregnancy is concerned, making sociocultural aspects which then are connected, invisible, because the focus the interaction between the professional and the woman is in the image and the "certainties" that are given by the machine. In such a dynamic, women, in a way, lose the ability to feature in the birth experience. They begin to have difficulty recognizing bodily changes that warned their grandmothers and their mothers that another baby was coming. If I began to get sick from chimarrão or coffee early in the morning, I knew I was pregnant. And when I stopped menstruating I knew I was pregnant again (Key Informant, 75); 'By my count, it's three months', says the key informant when I ask their gestational age"But let me show you the USG. I've done two, because the first did not work [...]. You know that we look and do not understand anything. 'I realize that there is no information about the gestational age, and then say that it seems they forgot to register. 'I can not forget to ask the doctor, so ...' (Field Journal. Key Informant, 24 years).

Knowing and dominating the body, as a way of supporting the signs, weakens itself in this PN medicalization situation. In this context, some women of the study group need the ratification of the technological apparatus to make interpretations that make their bodily manifestations and, therefore, depend on someone to decipher the test results, in this case a USG, which could be observed in a situation of prenatal consultation: a key informant delivers the the envelope containing the USG to the doctor and says, 'I did not understand the result of the USG, because I think I'm three months, but it has nothing written about it. I was curious and opened the exam. You know how it is ... I wanted to see how far gone I was so I opened it. The doctor says, 'you are the one who knows how many months you are, But let me see here, 'he says, looking at the report. 'yes ... there is an AG. Go to the office and leave it there to be fixed, it's all recorded on the computer '(Field diary. Key Informant, 24 years).

Through symbolic construction, a relationship whose power distribution is hierarchical is established, where women and their social groups are at a disadvantage and dependency of knowledge and medical authority, usually with devaluation of their knowledge, which puts them in a position 
of subalternity. The model is the basis of pre-natal, which is anchored in scientific rationality, biology and contributions of technological apparatus, ${ }^{7}$ as well as the contemporary trend of medicalization of life, contribute to undermine the woman's ability to resume a relationship with their bodies and mobilize internal and external structures of coping with the vicissitudes associated with PN (and it always present, since it is a facet of life). However, literature ${ }^{17}$ highlights that the uses of biomedical techniques and technologies cannot be considered as good or bad by themselves or as neutral social practices not involving distinct choices. These uses are mediators of relationships and so it is necessary to think about the role that medical technology represents in the order of care and in relations between the subjects. ${ }^{17}$

Hence the importance brings, along with the use of tougher technologies such as ultrasound examination, ensures women and their social groups, the experience of pregnancy, the access of others enabling the subject's expression, that is, lighter technologies such as listening, reading stories, learning with one another and negotiating. ${ }^{17}$ Through the association of this set of technologies, the expert, among them nurses, will learn an attention to nature humanistic nature, with results possibly more satisfactory to all who are part of the interaction of care.

It can be argued from there that the relevance of including the social and anthropological dimensions of birth as guiding axes of clinical practice, which would allow the understanding of the senses and meanings related to the experience of pregnancy, which are associated with the context of the life of rural women. This inclusion would enable the understanding of forms of care that women and their social groups use to operate their self-attention practices with a view to preserving the pregnancy as an event that symbolizes health.

\section{FINAL CONSIDERATIONS}

The study allows us to realize that the experience of pregnancy is a dynamic and multidimensional process, associated with social universes, clinical and symbolic of rural women, their social groups and SS experts. The understanding, symbols and meanings produced in the interaction of these different actors guide everybody in the interpretation of experiences relating to pregnancy and guide self-attention practices used in this stage of life.

The results point to the relevance of nurses and women being together in the field, they reflect on the potential benefits arising from the redemption of the body itself, as a domain of signs, whose interpretation, together with the critical and informed use of the obstetric technologies can strengthen them in the production of self-attention practices that contribute to the promotion of their health not only in the strict sense, but also in the lato sense.

The importance of efforts aimed at building symmetrical and democratic interaction spaces in obstetric care is highlighted, which symbolize sharing territories and re-articulation of different knowledge, which contributes to the equalization of leadership opportunities not only in pregnancy but in every process of birth.

The local character of this study is pointed out as one of the limitations of this study. However, saved the singularities of the study group, considering one of the rigorous scientific criteria it uses- transferability, the set of findings which may represent some self-attention practices relating to pregnancy practiced by a large number of Brazilian women, seeing as though Brazil is largely rural.

\section{REFERENCES}

1. Cardoso LSM, Mendes LL, Velasquez-Melendez G. Diferenças na atenção pré-natal nas áreas urbanas e rurais do Brasil: estudo transversal de base populacional. Rev Min Enferm. 2013. Jan-Mar; 17(1):85-92.

2. Ministério da Saúde (BR), Centro Brasileiro de Análise e Planejamento. Pesquisa nacional de demografia e saúde da criança e da mulher: dimensões do processo reprodutivo e da saúde da criança [Internet]. Brasília (DF): Ministério da Saúde. 2009. [cited 2012 Oct 10]. Available from: http://bvsms.saude.gov.br/bvs/ publicacoes/pnds_crianca_mulher.pdf

3. Jordan B, Anastasia T. Competing technologies in perinatal care: a call for dialogue between lowand high-tech practitioners. Anthropology News [Internet]. 2009 Mar; [cited 2015 May 09]; 50(3):5-6. Available from: http://onlinelibrary.wiley.com/ doi/10.1111/j.1556-3502.2009.50305.x/epdf

4. Capelli I. Risk and safety in context: medical pluralism and agency in childbirth in an Eastern Moroccan oásis. Midiwefery [Internet]. 2011 Dec; [cited 2015 May 09]; 27(6):781-5. Available from: http://www-periodicos-capes-gov-br.ez47. periodicos.capes.gov.br/index.php?option $=\mathrm{com}_{-}$ pmetabusca\&mn $=88 \& s m n=88 \&$ type $=m \&$ metalib =aHR0cDovL21scGx1cy5o b3N0ZWQuZXhsaWJya XNncm 91 c C 5 jb20vcH J p b 9 fbGlicm F y e S 9 s a W J 3 Z W I v Y W N 0 a W 9 u L 3 N 1 YXJjaC5kbz92aWQ9Q0FQRVM=\&Itemid=119

5. Van der Sand ICP, Monticelli M, Ressel LB, Bretas ACP, Schirmer J. Health anthropology: theoretical contributions to the interpretation of birth procedure. 
Rev Enferm UFPE [Internet]. 2014 Ago [cited 2015 Jan 4]; 8(8):2896-906. Available from: http:/ / www.revista. ufpe.br/revistaenfermagem/index.php/revista/ article/view/6581/pdf_5981

6. Menéndez Spina EL. Entrevista: Eduardo Luis Menéndez Spina. Trab Educ Saúde [Internet]. 2012. Jul-Out [cited 2013 Mai 02]; 10(2):335-45. Available from: http://www.scielo.br/pdf/tes/v10n2/09.pdf

7. Menéndez EL. Modelos de atención de los padecimientos: de exclusiones teóricas y articulaciones prácticas. Ciênc Saúde Coletiva [Internet]. 2003 [cited 2013 Mar 02]; 8(1):185-207. Available from: http:/ / www.ciesas.edu.mx/Publicaciones / diccionario/Diccionario \% 20CIESAS/TEMAS \% 20 PDF/Menendez\%2076c.pdf

8. Geertz C. A interpretação das culturas. $13^{\mathrm{a}}$ reimp. Rio de Janeiro (RJ): LTC; 2008.

9. Instituto Brasileiro de Geografia e Estatística (BR). Estados. Rio Grande do Sul. [Internet]. 2013. [cited 2013 Jul 22]. Available from: http://www.ibge.gov. br/estadosat/perfil.php?sigla=rs

10. Leininger M, Mc Farland M. Culture and diversity: a worldwide nursing theory. $2^{\mathrm{a}}$ ed. Boston (US): Jones and Bartlett Publishers; 2006.

11. Angrosino M. Etnografia e observação participante. Porto Alegre (RS): Artmed; 2009.

12. Martins M, Monticelli M, Diehl E. Cultural meanings of hypertension in pregnancy according to pregnant women. Texto Contexto Enferm [Internet] 2014 OutDez; [cited 2015 May 09]; 23(4):1004-12. Available from: http:/ / www.scielo.br/pdf/tce/v23n4/ pt_0104-0707-tce-23-04-01004.pdf

13. Outwater AH, Tarimo EAM, Miller JE, Campbell JC. Meanings of care by bereaved relatives of homicide victims in Dar es Salaam, Tanzania: implications for nursing. J Transcult Nurs [Internet]. 2012 Oct [cited 2015 May 09]; 23(4):397-405. Available from: http:// tcn.sagepub.com/content/23/4/397.full.pdf + html

14. Ministério da Saúde (BR). Conselho Nacional de Saúde, Comissão Nacional de Ética em Pesquisa. Resolução N. 196 de 10 de outubro de 1996: diretrizes e normas regulamentadoras de pesquisa envolvendo seres humanos. Brasília (DF): MS; 1996.

15. Chazan LK. “O aparelho é como um automóvel; a pista é a paciente". Para além do ensino de tecnologia no pré-natal. Physis [Internet]. 2011 [cited 2015 May 08]; 21(2):601-27. Available from: http:/ / www.scielo.br/ pdf/physis/v21n2/a14v21n2.pdf

16. Marques IC, Chazan LK. "Pra mim... são as montanhas rochosas..." consumo, espetáculo e muito mais no ultrassom obstétrico no Rio de Janeiro da virada do século. RECIIS - Rev Eletr Com Inf Inov Saúde [Internet]. 2009 [cited 2015 May 08]; 3(4):145-59. Available from: http://www.reciis.icict.fiocruz.br/ index.php/reciis/article/view/725/1370

17. Deslandes SF, Mitre RMA. Processo comunicativo e humanização em saúde. Interface - Comunic Saúde Educ [Internet]. 2009 [cited 2014 Feb 05]; 13(supl.1):641-9. Available from: http:/ / www.scielo. br/pdf/icse/v13s1/a15v13s1.pdf
Correspondence: Isabel Cristina Pacheco van der Sand Universidade Federal de Santa Maria Centro de Ensino Superior do Norte do RS Departamento de Ciências da Saúde Av. Independência, 3751

98300-000 - Vista Alegre, Palmeira das Missões, RS, Brasil E-mail: isabelvan@gmail.com
Received: June 01, 2015

Approved: November 27, 2015 